\title{
POSITION OF JMC GRADUATES: A TRACER STUDY
}

\author{
Dvilal Sharma
}

\begin{abstract}
s
The linkage between demand and supply of graduates instill a great significance in any study of higher education. The increasing trend of graduates may ultimately make the job market highly competitive. Due to high competition in job market there are high options for employer searching for new recruitment. To the best of study team, limited research has been carried out in higher education and none of the empirical studies have been found with regard to the absorption of the graduates in the job markets. Much of the studies discussed only challenges and policy intervention part. With this context, the status of graduates of JMC (a QAA Certified Institution) needs to be identified. It is widely believed that JMC has helped in building a nucleus of professionals in the related filed in Nepal and abroad. Though up-to-date information regarding the placement of JMC graduates is not available, it can be assumed that the graduates from $J M C$ have been working in the various positions in the field of service, manufacturing, academia, and $N G O / I N G O s$ sectors in reputed and well established national and international organizations in the country and abroad. The main objective of this study is to trace out the students who have graduated from $J M C$ as of 2009 to 2013 in various streams such as BBS, BBA, BA, B Sc and B Ed.The survey instrument was adapted from a questionnaire drafted by University Grants Commission Nepal, and it was slightly modified in its layout for the ease of handling. The questionnaire included both close-ended and openended questions. The expansion of higher education has increased the number of graduates entering into job market in Nepal and abroad. Graduates have felt easy to get enrollment in job market after attaining academic program in this campus. Graduates get insight in skills; attitude and knowledge for their job performance as well as improved work efficiency and communication skills after proceeding from this campus. Similarly the graduates have been able to improve their information technology skills and team spirit from the academic program offered by the campus.
\end{abstract}

Key Words: Tracer study, Autonomous Institution, Institutional Reforms, Interdisciplinary Approach, Enrollment, Problem Solving Skills.

\section{Background}

Ever growing population of Nepal is out of the causes of higher enrollment in higher education. Seeking for the job opportunities, Nepali graduates and under graduates spread over the Asia and rest of the part of the world. The expansion of higher education has increased the number of graduates entering into job markets in Nepal. The linkage between demand and supply of graduates instill a great significance in any study of higher education.

Education is generally perceived as one of the most well developed services to make the people more conscious cognitively. Education is an important indicator of national development. Nepal is running under the concepts of multi-university system, to produce skilled human resources and academic scholars since 1990. The human resource with the broader national development goals of the country has been the focus of higher education in recent years (Bajracharya, 2004).

Nepal has about one hundred year's history of higher education. In 1918, TrichandraCampus was established as the first higher education institution in the country affiliated to Patna University, India. The Tribhuwan University started in 1959 as the first university run by the government of Nepal. After its 
establishment, many colleges came into existence in various parts of the country and launched different programs. For promoting Sanskrit education, government of Nepal established Mahendra Sanskrit University in 1985. After restoration of democracy in 1990 under the concept of multi-university three more universities namely: Kathamandu University, Purbanchal University and Pokhara University were established and currently these universities have been offering various programs in different parts of the country. Recently government has established some other universities such as Lord Buddha University, Mid- Western Regional University, and Far- Western Regional University. However, these universities are not currently running any academic programs so far. This scenario suggests that though many tasks still remain, the tremendous expansion has been achieved in Nepal in higher education during the last two decades. In other words, the expansion of higher education has been growing in the recent years in Nepal. This also further raises a question that whether the present structure and pattern of higher educational development has served the community (SOB, 2010).

Janapriya Multiple Campus (JMC) was established with the active participation of local community including social workers, teachers, educationists, academics and social organizations. Shreejana Development Centre (SDC) and Janapriya Higher Secondary School (JHS) played an important to establish the Campus. Hundreds of meetings and interaction were held at SDC and JHS with the community people in the activization of SDC and the academics. Continued meetings and interaction materialized the objective of establishing a community based campus in this region. As a result, JMC came into existencein 2048 (1990).

$\mathrm{JMC}$ is an autonomous institution in every respect. However, as a TU affiliated Campus, JMC is governed by the TU's academic rules and regulations, curricula and examination. It has own premises of 9-7-3-3 (9 Ropani 7 Ana 3 Paisa 3 Dam) area with four distinct building blocks. Within these physical infrastructures, JMC has 126 teaching faculties, 47 Non-teaching staffs and 2940 Students in different programs. JMC has offered programs likeBachelor of Business Studies (BBS), Bachelor of Arts (BA), Bachelor of Business Administration (BBA), Bachelor of Education (BEd), Bachelor of Science (BSc) Master of Business Studies (MBS), and Master of Arts in sociology and English (MA). It has several academic Departments such as Department of Physics, Department of Chemistry, Department of Biology, Botany, Zoology, Microbiology and Environmental Science, Department of English, Department of Nepali, Department of Economics, Department of Social Studies and Department of Maths and Statistics, Department of Accounting and Financial Management, Department of General Management and Research and Department of Education.

According to the Campus Article of Association - 2048, (1991)5th amendment - 2066 (2009), chapter -5 , Article - 13, JMC has made the provision of selection committee to recruits the teaching and non teaching staff. The required number of teaching and non teaching staff is decided by the campus authority on the basis of demand of head of the departments and coordinators. The selection committee is responsible to recruit the teaching and non teaching staff. For the purpose of recruitment, notice is published in campus's notice board and also vacancy announcement notice is advertised in local/national newspapers. Written and oral examination are taken for permanent and oral exam and class observation method is followed to recruit the temporary teaching staff and oral and written examination is taken for non teaching staff.

JMC has clearly defined its goals, objectives and standards including background information, vision, mission and strategic plan. JMC has a community campus and operates under the management committee elected by the community people. The campus is a nonprofit and philanthropic organization, devoted to provide quality education to the students from the back-warded and disadvantaged society. The campus aims to bring forth highly qualified, well disciplined human resource befitting to the global 
market demand. JMC is endeavored to expand and strengthen the academic and job oriented programs with clearly defined practicable plans, programs and implementing strategies.

The expansion of higher education has increased the number of graduates entering into the job markets in Nepal. The linkage between demand and supply of graduates instill a great significance in any study of higher education. The increasing trend of graduates may ultimately make the job market highly competitive. Due to high competition in job market there are high options for employer searching for new recruitment. To the best of study team, limited research has been carried out in higher education and none of the empirical studies have been found with regard to the absorption of the graduates in the job markets. Much of the studies discussed only challenges and policy intervention part. With this context, the status of graduates of JMC (a QAA Certified Institution) needs to be identified.

It is widely believed that JMC has helped in building a nucleus of professionals in the related filed in Nepal and abroad. Though up-to-date information regarding the placement of JMC graduates is not available, it can be assumed that the graduates from JMC have been working in the various positions in the field of service, manufacturing, academia, and NGO/INGOs sectors in reputed and well established national and international organizations in the country and abroad. Furthermore, some of the graduates may have started their own business and some could have been helping in their family business. In this scenario, this study will explore the current status (employment, entrepreneurial, further education, social involvement, etc.) of the graduates of JMC and the efficacy of the knowledge and skills those graduates acquired during the study, in their executive, managerial, professional, further educational, and social life. The study will produce a very vital document for the university authorities, policy makers, planners and concerned bodies of the university to appraise globally competent management graduates in this globalized world. Similarly it will also help the university to fabricate university level alumni thereby using the network; the university can build the strong relationship with the different national and international organizations.

The main objective of this study is to trace out the students who have graduated from JMC as of 2009 to 2013 in various streams such as BBS, BBA, BA, B Sc and B Ed.

\section{Institutional Arrangements to Conduct the Study}

CMC meeting of JMC dated 2070-03-31 formulated the tracer study committee to conduct this research work. As per the instruction of $\mathrm{CMC}$, campus administration promptly organized meetings of the committee. And tracer study committee finalized questionnaire with the help of relevant consulting agencies. Field work has been carried out through collaborative efforts of all the faculties, non teaching staffs, and campus administration and tracer study committee. Report has been finalized by the committee by incorporating the suggestions provided by different stakeholders and dissemination seminar.

\section{Data and Methods}

For the purpose of this study graduates passed out and students who have taken character certificate of graduation duringthe academic years 2009 to 2013 have been taken into consideration. But in case of BBA students' certification in 2014 also has been included in this study.

This study initially tried to conduct the census of all students who had graduated from JMC during 2009-2013. However, due to limitations of the study out of 518 graduate during that period only 266 responses have been collected among which majority (34.60\%) were BBA graduates, 32\% were BBS graduates, $13.20 \%$ were BA graduates, $11.30 \%$ were B Sc graduates and remaining 9\% were B Ed graduates. The data were mainly collected from February 2014 to April 2014.

The survey instrument was adapted from a questionnaire drafted by University Grants Commission 
Nepal, and it was slightly modified in its layout for the ease of handling. Some additional information of the graduates was also incorporated in the questionnaire such that the JMC graduates could also be contacted easily in the days to come. The questionnaire included both close-ended and open-ended questions. The questionnaire comprised more than 50 items divided into five sections namely: student's personal information, first employment information, current employment status, past job experience, employer's verification, further study status, student's college records and other qualitative information section (see appendix D for tracer study questionnaire).

The questions were mainly asked by the faculty members, non teaching staffs, tracer study committee members of JMC (see appendix C)and interviews were conducted either face to face or in some cases the interviews were conducted through telephone conversation. In many cases, questionnaires were sent through e-mail and were returned to study team after being filled up. For this purpose, an official e-mail account was also used (ugc4jmc@yahoo.com). Furthermore, where direct contact or e-mail identities of the graduates were not available, a reliable source (mainly guardians' information or from the peer group) has also been incorporated to get the information of JMC graduates. In addition to the above mentioned approach we also used the social networking sites as face-book by which the study team was able to get the information from their peer group. Similarly couples of telephone calls and face book post have been made to requesting to fill up a questionnaire in time. The campus has organized the meeting with alumni in campus premises on 2070- 06-19 for the same purpose.

The data were collected by forming six groups; each group consists of two to three faculty members and non teaching staffs of JMC. Additionally non teaching staffs allowed special allowance to collect back the filled up questionnaire. In addition to that tracer study committee members have visited the possible places to meet the graduates several times. Normally it took 40-45 minutes to fill it up. Whenever possible, and also requested the graduates to submit the appointment letters, Id cards etc. Most of the respondents refused to provide such documents because of organizational confidentiality. They mentioned that appointment letter is confidential and thus cannot be provided. In such cases, further requested to provide a photocopy of their identity card or visiting card whichever is comfortable for them.

Before actually forming six groups in order to collect the data, a committee was formed by CMC, $\mathrm{JMC}$, consisting of four members (see appendix C). This committee prepared the roaster of all graduated students and then it was divided into the six groups that the data collection procedure would go smoothly. The newly formed committee made the decision of incorporating supporting staffs of JMC so that all official record of the graduates could be easily available. The tracer study committee organized several meetings and took the decisions to involve all faculty members, non teaching staffs who were employed at JMC at the time of committee formation (see appendix F for official letter).

All completed questionnaires were handed over to the coordinator of tracer study committee for data entry and processing. The data processing operations consisted of manual editing, coding, data entry, and machine editing. Data entry was carried out with the help of professionals who are well known about SPSS and its implications in order to minimize inconsistencies. The tentative coding scheme of questionnaire is given in appendix table E. The data was entered, edited, and analyzed using mainly SPSS 17.00 version software and MS-Excel, as well as MS-Words were also used to get easy result and reliable information to gather the result of filled up questionnaire. Data was entered directly from the questionnaires and was verified in order to minimize the errors.

Proportions or percentages have been computed and reported for all variables/indicators. Significance test has been done to determine the difference or association some variables using chi-square $\left(\chi^{2}\right)$ test. Because this study was designed to be descriptive assessment of JMC graduates, tests of significance has been conducted for limited number of factors. 


\section{Results \\ Background Characteristics of Respondents}

Out of total 266 questionnaire filled up, maximum respondent covered from BBA passed out students i.e. $34.60 \%$ similarly BBS passed out covered $32 \%$, BA passed out $13.20 \%$, B Sc passed out $11.30 \%$ and B Ed passed out is only $9 \%$.Out of total respondents $78.90 \%$ graduates from JMC are found upper caste people. In scheduled caste Gurung, Magar, Newar and lower no of Rai is included. Which consist of $19.50 \%$ which is so lower a percentage with compared to their enrollment in the campus. In lower caste people categorized as dalitis included of which only $1.50 \%$ graduates are found from JMC. Out of the total graduates from JMC $36.80 \%$ people are of rural people and $62.80 \%$ people are of urban area as reflected by table 2.3. However, enrollment statistics do not match with this statistics. It indicates that the people enrolled for higher education from rural areas have higher dropout ratio and have left the field without completing the degree. It may be another area for research.Female education in Nepal has highly been enhanced. Out of the total graduates from JMC 55.30\% are the females and 44.70\% are males. Enrollment statistics of the college also represents this statistics especially in the urban areas. Out of the filled up responses 8.6 percent of fathers and 25.2 percent of mothers have not got formal education at all. 15.4 percent of fathers and 36.1 percent of mothers have primary level education. Out of total responses 33.5 percent fathers and 25.6 percent of mothers are secondary level educated. As per the responses 38.7 percent fathers and nine percentmothers have got higher education. Out of the filled up responses 3.4 percent of fathers and 47.7 percent of mothers have not got formal occupation at all. 21.8 percent of fathers and 16.9 percent of mothersare depended on agriculture by profession. Out of total responses 66.9 percent fathers and 31.6 percent of mothers are professionals. Out of professional parents some are engaged in their business activities, some are government employees, and some of them have their own vocations.

\section{Employment status}

Out of total graduates $63.16 \%$ are employed and rest are unemployed. Out of total graduates 30.8 percent have got employment in public companies, 25.56 percent have got employment in private companies. The JMC graduates employment rate in $\mathrm{NGO} / \mathrm{INGO}$ is about 1.9 percent but government service is only 3.8 percent and very few no of graduates are engaged in business immediately after graduation.Most of the graduates, i.e. $18.8 \%$, are employed in bank and financial institutions. Rest areas of employment of JMC graduates areSchools, Showrooms, Hotels, Insurance, Airlines, Hydro powers, NGOs/INGOs, FM radios, Cooperatives, Projects, Factories, Childcares, Public and Private Companies. Least no of graduates are engaged on technical services like only 0.4 percent is engaged on nursing profession.Out of total respondent, 42.5 percent have got the full time employment. 2.3 percent graduates have got part time employment, 1.1 percent are engaged in self employment whereas 1.1 percent are in the field of teaching. Similarly 0.4 percent graduates are engaged on government service, industry and other areas. Out of employed graduates, 15 graduates are employed at senior level, 22 people at middle level, eight are at operational level. 73 graduates are employed at assistant level and two people have hot specified their designation. Out of the total graduates of JMC 7.52\% have got appointment for the job in fiscal year 2008/2009. Similarly 4.89\% graduates got their employment opportunity in 2009/2010 \& 2011/2012 each respectively. In fiscal year 2010/2011, 5.64\% graduates have got that opportunity. The highest enrollments in the jobs of the graduates have been in 2012/2013. In 2013/2014, 8.28\% graduates enrolled in their job markets but this number may increase by the end of this fiscal year. 


\section{Income and Job Status}

JMC graduates have spread over the various fields of job. From branch manager in the banks to security workers as well as in nursing and lab technician can also be found in the market. Out of various officials work most of the graduates work as tellers in the banks, credit department staffs, accountants as well as administrators also found in the market. Airlines, Hotels, Child care centre, Radios, Colleges, Schools(Principal/Teacher), Cooperatives (Manager), Fishery, Hydro power project, NGO/INGO, and Government offices have employed the past graduates. Similarly Public Companies, Private Firms, Schools, Showrooms, Departmental Stores, FM Radios, and Government Organizations are the major employers of JMC graduates.JMC graduates' earning level is found much varied. In values it is found annual income of graduates Rs. 70,000 to more than 6, 00,000. Most of the graduates' level of monthly income is around Rs. 10,000 , i.e. $27.3 \%$ responses were received in this regards.Only 9.8 percent of the graduates have faced problems while assigning the job. Out of total respondents 42.5 percent did not face problems at assigning the job. Maximum numbers of graduates have felt easy to assign job opportunity. They feel much helpful the content of syllabus to perform the assigned duties and responsibilities in their working field.Graduates' experience regarding their personal knowledge, skills, attitude enhance through academic program in relation to their job is very high. As per their responses 0.6 percent have not got knowledge and skills, 3.4 percent are not satisfied from the academic program. Out of total respondent 9.2 percent are satisfied, 21.9 percent feel good, 29.3 percent feel moderate and 19.5 percent feel very much useful the academic program to enhance the knowledge, skills and attitude required to proceed in job. As per the response of graduates they have got a lot of insight in job requirement through academic programs offered by the institution.Most of the graduates have improved their skills and result in job performance through academic programs offered by the institution. Out of total respondent 1.7 percent, 10.9 percent, 22.4 percent, 26.4 percent, 17.2 percent and 5.2 percent mentioned that not at all, not satisfactory, satisfactory, good, moderate and very much satisfactory respectively.Only 2.9 percent graduates have been unable to improve learning efficiency through the institutional effort. Out of total respondents 13.2 percent are satisfied 31 percent feel good, 3.8 percent are able to improve very much of their learning efficiency through institutional effort of JMC.Only 2.3 percent graduates have been unable to improve communication skills through the institutional effort. Out of total respondent 5.2 percent are not satisfied15.5 percent are satisfied 16.1 percent feel good, 25.9 percent improved moderately and 16.7 percent are able to improve very much of their communication skills through institutional effort of JMC. Out of total Graduates during study period 6.3 percent graduates have been unable to improve information technology skills through the institutional effort. Out of total respondent 14.9 percent are not satisfied 22.4 percent are satisfied 21.8 percent feel good, 12.1 percent improved moderately and 6.9 percent are able to improve very much of their information technology skills through institutional effort of JMC.Most of the graduates have improved their team spirits and team building in job performance through academic programs offered by the institution. Out of total respondents 2.3 percent, 8 percent, 14.9 percent, 21.8 percent, 20.1 percent and 15.5 percent mentioned not at all, not satisfactory, satisfactory, good, moderate and very much satisfactory respectively as the capacity building in maintaining team spirit.

\section{Graduates Persuasion for Further Study}

From this study 55.3 percent of total graduate are found enrolled in different academic programs of different universities. 44.7 percent graduates have not enrolled for higher education till the date. Out of enrolled graduates 19.6 percent students have enrolled in MBS, 12 percent in MBA, 8.2 percent in MSc, 7.5 percent in MA, 5.3 percent in M Ed, 0.4 percent in Dental, 0.4 Percent in MA Eco, 0.4 percent in MFC, 0.8 percent in MPA and 0.4 percent in MRA. From the above statistics most of the graduates have 
enrolled in management program.It can be seen that 55.6 percent of the graduates have enrolled in further study. Out of total respondents 4.5 percent have not enrolled in higher education and 39.8 percent are not interested to share this information.From above analysis it can be seen that 55.6 percent of the graduates have enrolled in further study. Out of total respondents 54.9 percent have got enrollment in masters' level and 0.8 percent have enrolled in other professional courses. But 39.8 percent are not interested to share this information.

\section{Academic Inputs towards Quality Measures of JMC and University.}

Maximum no. of graduates from BBA as well as other programsis satisfied with the no. of optional subjects offered by the institution. As per the response of BBA graduates 3.3 percent do not know about the matter, 6.5 percent are satisfied low, 21.7 percent perceive medium, 28.3 percent perceive satisfactory, 23.9 percent are satisfied moderately and 5.4 percent are satisfied very high with BBA syllabus. In other programs like BBS, B Ed., B Sc., and BA 2.9 percent do not apply with this information 8.6 percent have low level of satisfaction, 15.5 percent have medium level of satisfaction, and 20.7percent perceive moderate level of satisfaction and 8.6 percent are highly satisfied with the no. of optional subjects offered by the institution. Most of the graduates from BBA program as well as other programs are satisfied with the relevance of the program to graduates' professional requirements. As per the response of BBA graduates 1.1 percent do not know about it, 4.3 percent were satisfied low, 10.9 percent perceived medium, 27.2 percent perceived satisfactory, 33.7 satisfied moderately and 13 percent highly satisfied. In other program like BBS, B Ed., B Sc., and BA 2.3 percent did not know, 7.5 percent had low level of satisfaction, 16.1 percent had medium level of satisfaction, and 20.7percent satisfied with the matter, 28.7 percent perceived moderate level of satisfaction and 8.6 percent were highly satisfied with the relevance of course content and program with professional career. Large no of the graduates from BBA program as well as other programs are satisfied with the co-curricular activities. As per the response of BBA graduates 7.6 percent are satisfied low, 20.7 percent perceive medium, 33.7 percent perceive satisfactory, 21.7 percent are satisfied moderately and 7.6 percent are satisfied very high with those requirements. In other programs like BBS, B Ed., B Sc., and BA 22.4 percent have low level of satisfaction, 17.8 percent have medium level of satisfaction, and 8.6percent perceive moderate level of satisfaction and 6.9 percent are highly satisfied with the co-curricular activities.

Most of the graduates from BBA as well as other programs are satisfied with the knowledge gained for imparting problem solving skills. As per the response of BBA graduates 1.1 percent are satisfied low, 16.3 percent perceive medium, 35.9 percent perceive satisfactory, 26.1 satisfied moderately and 12 percent are satisfied very high with gained problem solving skills. In other programs like BBS, B Ed., B Sc., and BA 13.8 percent have low level of satisfaction, 17.2 percent have medium level of satisfaction, 25.9 percent are satisfied, and 19.0percent perceive moderate level of satisfaction and 10.9 percent are highly satisfied with the knowledge gained for imparting problem solving skills.Maximum no of the graduates from BBA as well as other programs are satisfied with inter disciplinary approach of learning from the range of course offered by universities. As per the response of BBA graduates 2.2 percent response do not have ideas regarding the matter, 14.1 percent perceive medium, 29.3 percent perceive satisfactory, 30.4 percent are satisfied moderately and 14.1 percent are satisfied very high with Inter disciplinary character. In other programs like BBS, B Ed., B Sc., and BA 1.7 percent of respondent do not have idea regarding the matter, 6.9 percent have low level of satisfaction, 19.5 percent have medium level of satisfaction, and 32.8 percent are satisfied with the matter, 16.7 percent perceive moderate level of satisfaction and 6.9 percent are highly satisfied with inter disciplinary approach of learning from the range of course offered by universities. Most of the graduates from BBA as well as other programs are feel that the institutional 
program is helped the graduates in work placement/attachment. As per the response of BBA graduates 12 percent are not benefited for their placement/attachment 9.8 percent satisfied low, 17.4 percent perceive medium, 21.7 percent perceive satisfactory, 19.6 percent are satisfied moderately and 9.8 percent are satisfied very high with work placement/attachment. In other programs like BBS, B Ed., B Sc., and BA 11.5 percent have not get insight for their placement, 14.9 percent have low level of satisfaction, 13.2 percent have medium level of satisfaction, 17.8 percent graduates are satisfied to get insight for their placement, and 16.1percent perceive moderate level of satisfaction and 9.2 percent are highly satisfied with the institutional program helped the graduates in work placement/attachment.

Most of the graduates from BBA as well as other programs are feel that the institutional program is much effective in creating better teaching learning environment. As per the response of BBA graduates 1.1 percent do not feel teaching learning environment fair, 6.5 percent are satisfied medium, 21.7 percent perceive medium, 45.7 percent perceive moderately satisfactory, 17.4 percent are satisfied very high with teaching learning environment of the campus. In other programs like BBS, B Ed., B Sc., and BA 1.7 percent have not feel teaching learning environment fair, 5.2 percent have low level of satisfaction, 10.3 percent have medium level of satisfaction, 25.9 percent graduates are satisfied with teaching learning environment of the campus, and 28.7.1percent perceive moderate level of satisfaction and 13.2 percent are highly satisfied with the institutional program much effective in creating better teaching learning environment.Majority of the graduates from BBA as well as other programs are satisfied with the quality of delivery from the faculties as well as services from the staffs. As per the responses of BBA graduates 2.2 percent graduates are not satisfied with delivery of service, 2.2 percent are satisfied low, 9.8 percent perceive medium, 26.1 percent perceive satisfactory, 37 percent are satisfied moderately and 15.2 percent are satisfied very high with delivery pattern. In other programs like BBS, B Ed., B Sc., and BA 1.1 percent graduates are not satisfied with delivery of service, 9.2 percent have low level of satisfaction, 10.9 percent have medium level of satisfaction, and 29.3 were satisfied with quality of service delivered, 25.9percent perceive moderate level of satisfaction and 9.2 percent are highly satisfied with the quality of delivery from the faculties as well as services from the staffs.Most of the graduates from BBA as well as other programs are satisfied with the fair relation with teaching faculties. As per the responses of BBA graduates 2.2 percent are satisfied low, 10.9 percent perceive medium, 10.9 percent perceive satisfactory, 22.8 percent are satisfied moderately and 42.4 percent are satisfied very high with Teacher student relationship. In other programs like BBS, B Ed., B Sc., and BA 0.6 percent graduates are not satisfied with teacher student relationship, 4.0 percent have low level of satisfaction, 11.5 percent have medium level of satisfaction, and 14.4 percent are satisfied with relation with faculties, 26.4 percent perceive moderate level of satisfaction and 27 percent are highly satisfied with the fair relation with teaching faculties. Most of the graduates from BBA as well as other programs are satisfied with the laboratory and library facilities. As per the responses of BBA graduates 3.3 percent are satisfied low, 8.7 percent perceive medium, 10.9 percent perceive satisfactory, 34.8 percent are satisfied moderately and 30.4 percent are satisfied very high with such facility. In other programs like BBS, B Ed., B Sc., and BA 1.7 percent graduates are not satisfied with student teacher relation, 4 percent have low level of satisfaction, 8.6 percent have medium level of satisfaction, and 17.8 are satisfied with lab/library facilities, 30.5 percent perceive moderate level of satisfaction and 21.3 percent are highly satisfied with the laboratory and library facilities. Academic program and courses offered by JMC have a significant role in enhancing the capability of graduates and their job placement.

\section{Implications to Institutional Reforms}

Since its inception, the college has been struggling for the enhancement of the quality. A majority 
of the graduates either have got good jobs or acquiring further degree in national and international universities. Besides the best achievement in academic excellence, this study has pointed out some of the important serious concerns that are to be addressed in the days to come.

The study shows that majority of the graduates are from the management streams, therefore an attention is to be paid to increase the number of students in other streams (B.Ed, BSc, BA). Immediate institutional reform may be beneficial for attracting in these streams.Similarly, the caste wise composition of graduates does not seem inclusive; therefore the management should be aware to attract the students from dalit and other marginalized communities of the societies by formulating attractive policies. The result of the study is encouraging that a higher proportion of pass-out graduates are female (more than 55.0 percent of female against 45 percent). The current policy needs to continue.The result of the study also reveals that the skill of the graduates is salable in local market, particularly in banking sector, school, public college, insurance company and others. However, the qualitative exploration suggests that further skillful professional training may be best option for competing with other graduates in the local as well as national market. Therefore, additional professional training may be an immediate action to be taken for widening the horizon of skills.

Although a higher proportion of students rate the institution as the good place for getting personal, knowledge, skills and enhanced attitudes, some of the graduates are not positive towards academic enhancement; therefore, an attention is to be paid to address these problems.In terms of learning efficiency, less than 15.0 percent of graduates report that they are very much satisfied with the learning efficiency but majority of the graduates' favor that the learning efficiency is lower than moderate level. It is, therefore, imperative that effective and improved teaching learning activities are to be adopted to fulfill the expectation of graduates in the coming days.It is well known fact that improved information technological skill is one of the assets of the graduates in competitive market in Nepal as well. The study reveals that majority of the graduates do not acquire very good skills, therefore, a reform is essential for improving improved information technological skills. The outcomes of the study clearly indicate that teaching and learning environment is satisfactory as expected, therefore a reform is required in terms of teaching materials, teaching pedagogy and quality improvement of the faculties.

\section{Conclusions}

JMC was established in 1990 in participation of local community, including social workers, teachers, educationists, academics and social organizations. Having own premises, building and sufficient infrastructure, accredited from UGC Nepal, JMC has been offering quality education in various fields such as Management, Humanities, Science and Education of bachelor and master level. This study has explored the situation of JMC.

The expansion of higher education has increased the number of graduates entering into job market in Nepal and abroad. In this context, the status of graduates of JMC needs to be identified. The students graduated from 2009 to 2013 in various streams in this campus have been considered as respondents. The interesting conclusions can be drawn based on the findings of the study.

$>$ The result of the study shows that proportionate respondentsare taken from every stream. However, maximum graduates during study period were found from management stream.

$>$ It was also concluded that, maximum no.of graduates represent upper caste, urban area and female. Similarly parents of graduates have medium level (secondary/ intermediate) of education. By profession, parents of graduates are involved somewhere in generating revenue either in business or in employment.

$>$ From the finding of the study maximum no of graduates $(63.16 \%)$ are involved in job market in 
various fields. Most of the graduates are employed in banking industry (18.8\%) and other areas of employment are schools, showrooms, hotels, insurance, airlines, projects, factories, trading houses, childcare, hydro power, dental, nursing etc.

$>$ Out of employed graduates majorityare full time (i.e. $42.5 \%$ of total respondents). Graduates from JMC involved in senior level to assistant level and by appointment, highest no of graduate are appointed in F/Y 2012/13.

Darning level of graduates is found much varying (from Rs. 70,000 p.a. to 6,00,000 p.a.) but average compensation received by them was Rs. 150,000p.a.

$>$ Graduates have felt easy to get enrollment in job market after attaining academic program in this campus. Graduates get insight in skills; attitude and knowledge for their job performance as well as improved work efficiency and communication skills after proceeding from this campus. Similarly the graduates have been able to improve their information technology skills and team spirit from the academic program offered by the campus.

$>$ Maximum graduates (i.e. 55.3\%) have enrolled in different academic program of different universities. Out of these graduates, maximum no of graduates have enrolled in management (i.e. MBS and MBA) and another master programs.

$>$ Course offered by the campus is sufficient, no of optional subjects also is sufficient, program is more relevantto professional requirements, co-curricular activities are found sufficient, graduates are found to have improved in acquiring knowledge, skills, and problem solving skills through courses offered by the campus and university.

$>$ As per the findings, Bachelor syllabus and college's efforts are full of interdisciplinary approach, graduates are helped more in locating work placement/attachment, teaching learning environment is good, delivery of faculties is also appropriate, service of lab/library is found effective and better teacher student relation is maintained.

\section{Recommendations}

On the basis of the results of this study,and conclusion drawn previously, following recommendation have been provided to concerned authorities.

$>$ Majority of the graduates involved in job market. However, to produced saleable output in full, campus should initiate the non credit vocational courses and training on demand of the graduates.

$>$ Campus should try to conduct the census covering all the graduates to obtain the complete and clear result.

$>$ Since enrollment rate of graduates in management stream is higher, effective plan and policies should be initiated to attract higher no of students in rest of the streams.

$>$ Job-placement-cell should be empowered and activated to assist graduates in searching and joining the job.

$>$ Independent academic audit should be initiated by the campus and concerned University as well as UGC each year to confine the market requirement, students' expectation, well equipped output of the program and linking the course offered with graduates' requirement, methodology of delivery as well as pedagogy.

$>$ Future study can be carried out by incorporating many other factors such as students' performance which can be measured by their score, family status, and so on. The University Grant Commission (UGC), of Nepal should initiate for further professional and holistic research that can be carried out in the days to come. For this, UGC can from a coordination committee incorporating research oriented faculties from the different universities of Nepal, free lancing academicians, as well as the 
researchers from different organizations.

\section{References}

Bajracharaya, H. R.,(2004). Higher education and challenges of National Development.Education and Development. Kathmandu: UGC, Nepal.

CRRC., (2012). Tracer Study of Recent Graduates from Vocational Institution in Kotayk and Ararat Marzes of Armenia. United States of America: European Training Foundation and Caucasus Research Resource Centre, A Program of the European Partnership Foundation.

JMC., (Various Years). BBA Brochures. Pokhara: Janapriya Multiple Campus.

JMC., (2010). MBS Brochure. Pokhara: Janapriya Multiple Campus.

SOB., (2010). Management Graduates of School of Business Pokhara University. Pokhara: Faculty of Management, Pokhara University.

https://www.docstoc.com/pass?docId=129105558\&download=1 